\title{
Os cafés como espaços de comunicação
}

\author{
Glauco Rodrigues Cortez
}

Resumo

O presente artigo analisa a importância dos Cafés, durante os séculos XVII e XVIII, para a constituição dos espaços de comunicação. Eles aparecem como uma radical transformação no espaço da mediação social porque, pela primeira vez, esse espaço é reivindicado por particulares. $\mathrm{O}$ artigo procura mostrar como foi possível essa mudança, ou seja, como a presença de instrumentos como igualdade, diálogo e capacidade de reunir diferenças foram fundamentais para sua legitimação como espaço de mediação social. Além disso, analisa os clubes privados e sua incapacidade para se constituir como espaço de mediação social.

Palauras-chave:

Cafés, Espaço público, Comunicação, Mídia

\section{Coffee houses as spaces of communication}

\section{Abstract}

Sobre 0 autor

Doutor em Ciências Sociais pela Universidade de Campinas (Unicamp), professor da Pontificia Universidade Católica de Campinas (PUC-Campinas). glauco_cortez@yahoo.com.br
The present article analyzes the importance of the Cafés, during the XVII and XVIII centuries, for the constitution of the Spaces of Communication. They appear as a radical transformation in the space of social mediation because, for the first time, this space is demanded particularly. The article tries to show how this change was possible, or either, how the presence of instruments such as equality, dialogue and capacity to congregate differences that were basic for its legitimating as space of social mediation. Moreover, it analyzes the private clubs and its incapacity to consist as spaces of social mediation.

Key words:

Coffee-houses, Public space, Communication, Media 
Os cafés dos séculos XVII e XVIII representam uma época em que a sociedade experimentava uma comunicação sem mídia. Eles formavam pontos de encontro e de sociabilidade comuns em praticamente toda a Europa, mas principalmente em Londres e Paris. A comunicação presente nos cafés constituía um diálogo efetivo entre interlocutores de classes sociais distintas e, também por isso, eles tornaram-se centros de informação jornalística e literária. Entre a primeira e a segunda década do século XVIII há no mínimo 500 cafés em Londres. Paris teria cerca de 300 cafés na metade do século XVIII e cerca de 600 no final (1787). Istambul era famosa já no século XVI pelos cafés, cerca de 600 .

Há uma cultura social da comunicação que se estabelece pelo continente europeu. Na Irlanda, por exemplo, os pubs eram tidos como lugares onde as notícias importantes do distrito propagavam-se. "A conversação nesses locais era tão longa quanto genérica, e os oradores eram persistentes em seus fraseados." (Arensberg; Kinball,1940, apud Stephens, 1993:99). Ao reconstruir parte das atividades cotidianas dos cafés, pode-se conceituar o entendimento sobre os espaços de comunicação.

Como centro de informação, os cafés tornaram-se naturalmente locais onde floresciam discursos, diálogos e diferentes tipos de narrativas definidas dentro das regras estabelecidas pelo proprietário da loja, uma espécie de manual de comportamento. Essas regras são bastante ilustrativas para entendermos o seu caráter cultural e a sua legitimidade. A partir do momento em que se definem regras para o diálogo, há entre os participantes uma certa aceitação dos procedimentos. Para Sennet, era comum a seguinte regra: quando um homem entrava no recinto, encaminhava-se diretamente ao bar, pagava um penny e era avisado, caso nunca tivesse estado lá antes, sobre os regulamentos da casa. Por exemplo, não cuspir nesta ou naquela parede, não brigar perto das janelas etc. "E então se sentava para se divertir. Isto, por sua vez, consistia em conversar com outras pessoas" (Sennet, 2002:108).

A conversa tinha um caráter democrático, como se as pessoas estivessem em uma praça pública, talvez até mais acentuado. Ela era comandada por regras bastante específicas, espécie de manual de redação:

A fim de que as informações fossem as mais completas possíveis, suspendiam-se temporariamente todas as distinções de estrato social; qualquer pessoa que estivesse sentada num café tinha o direito de conversa com quem quer que fosse, abordar qualquer assunto, quer conhecesse as outras pessoas, quer não, quer fosse instada a falar, quer não. Era desaconselhável fazer referências às origens sociais das pessoas com quem se falava no café, porque isso poderia ser obstáculo ao livre fluxo da conversa. (Sennet, op. cit.: 108/109.)
Ao reconstruir parte das atividades cotidianas dos cafés, pode-se conceituar o entendimento sobre os espaços de comunicação 
Apesar de serem espaços privados, os cafés instalam uma radical democracia entre os interlocutores. É o momento de aplainar as diferenças de classe na comunicação; um momento de superação da consciência de classe como parte do processo da esfera pública burguesa, como definiu Habermas (1984). Os cafés aspiram ser o espaço mediador do diálogo entre as classes sociais. As regras desses manuais de diálogo e comportamento anseiam por um espaço de neutralidade, isenção e independência em relação aos usuários. A sua força social está exatamente na capacidade de reunir as diferenças. Esse é um aspecto chave para se entender os espaços de comunicação, conceito desenvolvido sobre a teoria dos espaços mediadores culturais e que serve de metodologia para a compreensão do jornalismo e da mídia contemporânea como um todo ${ }^{1}$.

Uma outra característica interessante dos cafés, e muito semelhante aos padrões de produção jornalística contemporânea, são o que se pode chamar de "segmentação editorial". A grande expansão e a sua característica como um espaço múltiplo fez com que os cafés adaptassem uma loja específica para cada profissão, ramo do comércio, classe social e ou partido político. Assim, como futuramente aconteceria com os jornais e revistas, os cafés tiveram uma versão segmentada em um tipo de público, ainda que houvesse a liberdade para entrar e participar do diálogo em qualquer estabelecimento. É muito provável que muitos e assíduos freqüentadores passassem por vários cafés. No entanto,

Os juristas discutiam sobre Direito ou assuntos eruditos...no café Nando`s ou no Grecian... As pessoas da City se encontravam no Garraway`s ou no Jonathan`s para discutir a alta e a baixa das ações e verificar a taxa de seguros. Os religiosos conversavam no Trusy`s ou no Child`s sobre as fofocas da Universidade...Os soldados se reuniam depois do serviço no Old ou no Young Man`s... O St. James`ou o Smyrna eram o quartel-general dos políticos... Os escoceses tinham seus encontros no Forest`s. Os franceses, no Gile`s ou no Old Slaughter`s... Os intelectuais da moda runiam-se no Will`s, no Button`s ou no Tom`s... No Lloyd`s, os comerciantes mais abonados... Os amigos das artes honravam a cafeteria Don Saltero em Cheyne Walk. (Cf. relato na National Review, n॰ 8, apud Habermas, 1984: 299/300.)

O café Mile's, também em Londres, se especializou em política. Um observador anotou que as discussões no parlamento inglês eram fracas se comparadas aos discursos no Mile's (Sthephens, 1993: 102). Até votações, espécie de consulta pública sobre temas de interesse da sociedade, havia por lá.

${ }^{1} \mathrm{O}$ espaço mediador cultural pode ser definido como o espaço materializador da comunicação que envolve múltiplos aspectos de uma sociedade, inclusive sua capacidade de transformação. Ele pode ser definido também como um espaço que se torna substância e processo cultural dinamizados pela comunicação e capaz de absorver e distribuir de forma proeminente a dinâmica superestrutural da sociedade. A respeito do espaço mediador cultural ver Cortez, 2005.

\footnotetext{
Estudos em Jornalismo e Mídia - Ano V - n. 2 pp. XX - XX jul./ dez. 2008
} 
A totalidade dos cafés forma um grande sistema de concentração e difusão de informação e estabelece uma relação estreita e contraditória com os nascentes jornais. Em certo período era comum a leitura de jornais em voz alta e em rodas no interior das cafeterias. Na virada para o XVIII, proprietários de cafés londrinos passaram a editar e imprimir seus próprios jornais, reivindicando, em 1729, o monopólio desse ramo. A relação era tão intensa entre café e jornal que alguns jornais nasceram com a palavra café no próprio nome. Em Leipizig foi fundado um diário em 1689 com o nome de The Curious Coffehouse of Venice e, em Milão, surgiu em 1764 o jornal Il Caffè (Burke; Briggs, 2004: 41). As revistas de crítica literária e crítica de arte, tão importantes para o auto-esclarecimento do público no processo da esfera pública burguesa, também se confundem com a vida dos cafés, afirma Habermas (op. cit.). Um dos exemplos citados pelo autor é a Tatler, que se volta expressamente para os valorosos cidadãos que vivem mais nos cafés que em seus estabelecimentos comerciais. Para o autor, "as novas revistas estão ligadas tão intimamente com a vida dos cafés que esta poderia ser reconstruída através de cada número" (Habermas, op. cit.: 59).

Descrevendo as curiosidades de Paris no ano de 1787, Dulaure anota que nada agrada tanto aos estrangeiros como os bons cafés, onde podiam descansar, ler periódicos, divertir-se com jogos, aquecer-se no inverno, refrescar-se no verão e ainda ouvir a fala dos novidadeiros (Dulaure, 1787, apud Rizzini, 1977:76) ${ }^{2}$.

Um novidadeiro fidedigno recebia epístolas ou periódicos de fora, como o conde Joachim de Lonne, presidente dos Faladores das Tulheiras, e, do porte de cartas, gazetas e informações, passavam a divulgá-las nos cafés e em outros lugares da cidade. Esses primeiros jornalistas atuavam em locais pré-estabelecidos. "A bolsa de notícias de Paris funcionava em pontos fixos: Luxemburgo, Pallasi-Roual, Tulheiras, Galerie du Palais, Pont Neuf e claustros dos agostinhos, beneditinos e franciscanos" (Rizzini, op. cit.:77). Para Rizzini, os novidadeiros, redatores de cartas e gazeteiros agiam como verdadeiros repórteres. Assim os define nesse texto peculiar:

\begin{abstract}
Milhafres à cata de assunto, empoleiravam-se os repórteres nos corredores e copas dos palácios e antecâmaras das embaixadas; esvoaçavam nas praças, adros e claustros; pousavam nos cafés e bodegas; papagueavam com lacaios e boleeiros, recorrendo à indiscrição, à espionagem, à peita, para bicar a novidade. (ibd.: 87.)
\end{abstract}

Mumford, em A História das Cidades (1998), assinala que, à medida que a cidade do final da Idade Média se desenvolve, ela passa a ser uma rede de comunicação. Essa rede se estabelece em espaços de comunicação ou pontos de encontros e paradas de
${ }^{2}$ Os novidadeiros eram pessoas que divulgavam cartas e gazetas manuscritas. Eles tinham assento privilegiado nos cafés nos séculos XVII e XVIII. 
seus habitantes e de viajantes. Os cafés e sua disseminação pela cidade servem de pontos de comunicação e informação importantes para as mais variadas necessidades da comunidade e de pessoas que por lá passavam:

Os mexericos junto do poço ou da bomba da aldeia, a conversa na taverna ou no lavadouro, as proclamações dos mensageiros e arautos, as confidências dos amigos, os rumores da bolsa e do mercado, o intercurso guardado dos eruditos, o intercâmbio das cartas e informações, notas e contas, a multiplicação dos livros - tudo isso são atividades centrais da cidade. (Mumford, 1998:76.)

O desenvolvimento das cidades e da indústria gráfica fez com que jornais e cafés, que tinham interesses e objetivos tão próximos, iniciassem uma disputa pela hegemonia dos espaços de comunicação. Inicia-se uma verdadeira batalha, dentro de um âmbito privado entre cafés e jornais, pelo controle do espaço mediador cultural, que está bem documentada. Textos mostram que os proprietários de cafés reclamam na primeira metade do século XVIII dos "coletores" de notícias domésticas, espécie de repórteres pagos por proprietários de jornais independentes e não ligados a comerciantes do ramo do café.

\footnotetext{
Pessoas estão sendo empregadas (uma ou duas para cada jornal), ganhando um tanto por semana, para rondarem os cafés e imiscuíremse em companhias onde não são conhecidas; ou para ficarem plantadas a uma distância conveniente, ouvirem o que está sendo dito, com o fim de apanhar material para os jornais... As mesmas pessoas estão sendo contratadas para travarem conhecimento com os lacaios e outros criados da nobreza e da pequena fidalguia... As mesmas pessoas se deixam ficar ociosas nas repartições públicas, como arrombadores, esperando um encontro com um pequeno funcionário, ou uma conferência com um porteiro, para poderem conseguir uma pequena notícia... para o que despendem um shilling. (Cf. "Homens-de-café", citado por Stephens, 1993: 523/524.)
}

Os proprietários de jornais, no entanto, negavam a atividade de jornalista remunerado, e apenas admitiam conceder um salário por "bom aconselhamento".

Essa relação aponta para os primórdios da reportagem e, de certa forma, como ela descende de um espaço de mediação cultural oriundo dos cafés do início do capitalismo. O espaço ocupado pelas praças, por outros lugares públicos e pelos cafés, que tanto se desenvolvem naquele período, são essencialmente orais. Toda a informação presente nesses espaços de comunicação é transmitida verbalmente, o que, de certa forma, permite a participação

Estudos em Jornalismo e Mídia - Ano V - n. 2 pp. XX - XX jul./ dez. 2008 
de uma grande quantidade de pessoas não alfabetizadas. No entanto, há um movimento inevitável e contínuo que começa a disputar a legitimidade desse espaço social. É um movimento que emerge junto com uma sociedade que se industrializa e se torna letrada, desenvolve tecnologia de impressão, implanta sistemas postais mais eficientes e, por fim, necessita da criação de um novo espaço de comunicação. Esse novo espaço será radicalmente diferente: ele deixa de ser um espaço físico e imóvel como os cafés e passa a ser um objeto que se multiplica e se dissemina por vários locais da sociedade.

Os cafés tiveram seu tempo áureo como espaço de comunicação, mas começaram a perder vitalidade no fim do século XVIII. Segundo Sennet, parte do declínio dos cafés acontece por razões econômicas, quando a Companhia das Índias Orientais Britânicas tornou-se importadora de chá e impôs uma nova moda, que deixava de fora as cafeterias. "Os comerciantes dos cafés não tinham licença régia para o chá” (Sennet, 2002: 110). Mas essa mudança não seria capaz de desestabilizar a sociabilidade criada nesses locais durante séculos. A vida dos cafés continuou nas estalagens de paradas de diligências e também nos bares e nos pubs, que serviam de pontos de reunião próximos aos teatros. Na realidade, foram os avanços econômicos, transformações políticas e sociais, desenvolvimento tecnológico e outros que confluíram para esmaecer a presença do café na sociedade. $\mathrm{Na}$ análise dos espaços de comunicação, os cafés declinaram porque, concomitante a essas transformações, eles deixaram de ser espaços mediadores culturais em decorrência da consolidação dos jornais.

Antes do declínio, contudo, os donos de cafés enfrentaram uma concorrência com os clubes privados, na qual saíram vencedores. A história dos clubes, como tentativa de se construir espaços de comunicação, é bastante ilustrativa porque demonstra a força que os cafés tinham na época.

Os clubes surgem porque parte da elite da sociedade nascente, no anseio do sucesso econômico capitalista, tenta construir espaços mediadores essencialmente privados. Eles surgem como um fórum alternativo aos cafés. Os clubes foram criados com a idéia de que o discurso traria maior prazer quando se tivesse selecionado a platéia e os interlocutores, excluindo-se aqueles cujas vidas pessoais eram desagradáveis ou alheias. Almejavam uma comunicação sem ruído, pura. "A privacidade significava que o discurso só poderia ser agradável caso se controlasse com quem se estava falando" (Sennet, op. cit.: 112), e os cafés se opunham a esse tipo de segregação. Com esse objetivo, claro que o clube nunca chegaria a ser um espaço mediador cultural - e talvez por isso tenha tido nesse formato uma vida curta, de algumas décadas.

Na análise dos
espaços de
comunicação, os
cafés declinaram
porque deixaram
de ser espaços
mediadores
culturais em
decorrência da
consolidação dos
jornais

Na análise dos

espaços de comunicação, os cafés declinaram de ser espaços mediadores culturais em decorrência da jornais 
O legado dos clubes mostra que o excesso do mundo privado enfraquece o espaço mediador, o qual perde o seu sentido dialógico e aberto à participação. Essa era uma característica marcante dos cafés; ali sempre se conhecia algo novo, diferente, com narradores e novidadeiros com boa bagagem de notícias e estilos de linguagem, além de possibilitar um diálogo de contra-argumentos. Esse processo de abertura para novidade, para o inusitado e para o contraditório era uma característica presente tanto nas praças públicas da Idade Média quanto na ágora Antiga. Eram espaços abertos ao acesso de qualquer pessoa, que sempre os enriqueciam com novas narrativas, fatos inusitados e com pensamentos antagônicos. $\mathrm{O}$ encontro ou o embate de idéias entre pessoas diferentes tende a causar certo desconforto. Esse é o paradoxo e a essência dos espaços de comunicação: é do antagonismo, da contradição e do desconforto com o embate de idéias que surge a sua força comunicacional.

O clube tenta eliminar esse antagonismo; nasce em oposição a isso. Ele se caracteriza pela afinidade, pela semelhança e pela proximidade de pensamentos e idéias. Ele nivela toda a rugosidade social e, com isso, torna a mediação supérflua. Quando se está com amigos em um clube, os conflitos são aplainados e as chances de se descobrir o que está acontecendo no vasto mundo exterior são bem mais restritas do que nos espaços dos cafés. As versões, ainda que diferentes, parecem sair de uma mesma matriz de pensamento. Sem o contraditório, só redundância e fantasias podem crescer. As limitações dos clubes logo provocaram tédio, como se vê nesta declaração de Oliver Goldsmith aos membros do Turk's Head Club, em 1773: "Seria uma agradável variação (aumentar o clube), pois já não se pode haver nada de novo em nosso meio: já viajamos um por um por todas as nossas cabeças!" (Sennet, op. cit.: 112). O espaço mediador cultural não pode existir em um ambiente de raro fluxo com o mundo exterior, com o desconhecido e distante de um processo dialético e de premissas contraditórias. Essa abertura e processo são o fermento utópico dos espaços mediadores. A rápida falência dos clubes, enquanto difusores de informação, linguagem e conhecimento, explica em certo sentido a essência ou natureza pública dos espaços de comunicação.

A sociedade dos séculos XVII, XVIII e XIX, que reivindica participação política e cultural dentro da chamada esfera pública burguesa, é uma sociedade que está em plena revolução industrial e cultural com expansão do aprendizado técnico e da alfabetização. Aos poucos, os novos espaços de mediação cultural vão abandonar definitivamente o espaço geográfico, independente de serem centrais ou espalhados pela cidade. $\mathrm{O}$ novo espaço mediador é caracterizado pela técnica, fruto de um
Esse é o paradoxo dos espaços de comunicação: é do antagonismo e do desconforto com o embate de idéias que surge a sua força comunicacional 
processo industrial que permite o desenvolvimento de produtos como o papel e a tinta em larga escala. Esses novos espaços de comunicação, fundados sobre a democratização da escrita, serão conhecidos como gazetas manuscritas, cartas noticiosas e, mais tarde, os jornais propriamente ditos.

A sociabilidade face a face, a contigüidade física - marcas do espaço mediador cultural até o período áureo dos cafés - vai se transformar em uma nova forma de convívio com a chegada do que se pode denominar de espaço veicular, seja em forma de cartas ou jornais. Apesar de manterem uma relação pública com a sociedade - um espaço democrático, de diálogo e de livre acesso, o que o permite caracterizá-lo mediadores culturais -, esses espaços de comunicação se transformam em um bem material, dentro do modelo industrial nascente. Com isso, e é importante notar tal característica, esses novos espaços manterão, assim como faziam os cafés, o seu caráter ou controle privado.

O espaço de comunicação, portanto, é um espaço em que acontecem ou são representadas as ações da sociedade. Nas sociedades antigas, a ágora e o fórum romano aparecem como exemplos dessa multiplicidade de ações. Na Idade Média, são as praças públicas e posteriormente os cafés. No entanto, essas ações sobre os espaços de comunicação são essencialmente ações de comunicação com diversas finalidades - comércio, educação, locomoção, afetividade, legislação, poder, política etc - e que mantêm um processo histórico e de transformação constante. Esse processo de transformação é um continuum social que só é interrompido em momentos dramáticos como catástrofes, guerras e ou revoluções e, por isso, é o processo que aparece de forma bastante distintas em diversas sociedades.

O espaço de comunicação pode ser definido também como um padrão da vida coletiva, mas não um aspecto determinante. A comunicação, nesse sentido, é a energia desse processo que movimenta e orienta as ações da coletividade. Por isso, quando uma sociedade dá um salto entre uma cultura oral para uma cultura escrita ou quando distende os espaços com conquistas territoriais, há uma necessária transformação no espaço de comunicação, ou seja, é preciso criar novas formas e tecnologias para se ter uma reordenação desse espaço. O mais importante, para a compreensão do sentido dialógico do espaço de comunicação, é reconhecer que ele só pode existir se houver uma capacidade ou uma aspiração à heterogeneidade, à diferença e a uma dialética comunicacional, mesmo que esse processo seja carregado pela hegemonia da classe ordenadora desses espaços.
O mais

importante, para

a compreensão do

sentido dialógico

do espaço de

comunicação,

é reconhecer

que ele só pode

existir se houver

uma aspiração à

heterogeneidade

\section{Estudos em Jornalismo e Mídia - Ano V - n. 2 pp. XX - XX jul./ dez. 2008}




\section{Referências}

BURKE, Peter; BRIGGS, Asa. Uma História Social da Mídia. Rio de Janeiro: Zahar, 2004.

CORTEZ, Glauco Rodrigues. O Espaço da Comunicação. Campinas: Tese de Doutorado/IFCH/Unicamp, 2005.

GLOTZ, Gustave. A Cidade Grega. Rio de Janeiro: Difel, 1980.

HABERMAS, Jügen. Mudança Estrutural na Esfera Pública. Rio de Janeiro: Tempo Brasileiro, 1984.

MUMFORD, Lewis. A Cidade na História. São Paulo: Martins Fontes, 1998.

RIZZINI, Carlos. O Jornalismo Antes da Tipografia. São Paulo: Companhia Editora Nacional, 1977.

SENNET, Richard. O Declínio do Homem Público: as tiranias da intimidade. São Paulo: Cia. das Letras, 2002.

STEPHENS, Mitchel. Uma História das Comunicações: dos tantãs aos satélites. Rio de Janeiro: Civilização Brasileira, 1993.

Recebido em 30 de agosto de 2008 Aprovado em 25 de outubro de 2008 